\title{
BAILEU: KAJIAN TENTANG BENTUK MANIFESTASI FISIK DARI MASYARAKAT ADAT DI KECAMATAN PULAU SAPARUA
}

\author{
Baileu: The Study of Physical Manifestation Form of Traditional \\ Community at Saparua Island District
}

\author{
Andrew Huwae \\ Balai Arkeologi Ambon \\ J1. Namalatu-Latuhalat, Nusaniwe, Ambon-97118 \\ Andrew_huwae@yahoo.co.id
}

\begin{abstract}
Abstrak
Keadaan identitas Baileu di wilayah Kecamatan Pulau Saparua saat ini dalam keadaan cenderung rusak karakter budayanya, dan kalau berkelanjutan akan menjadi hilang, untuk itu menemukan kembali jati diri dapat membangun pemahaman tentang karakter budaya sebenarnya. Pada beberapa desa yang dijumpai di wilayah Kecamatan Pulau Saparua, kesadaran dan karakter tradisional tersebut sudah mulai hilang. Hal ini tergambar dari keadaan arsitektur yang lebih modern, serta kurang perhatian dari masyarakat pendukungnya. Hal ini sesuai dengan fakta bahwa perubahan-perubahan besar telah terjadi dalam system adat di desa-desa kecamatan Pulau Saparua dan hanya unsur-unsur atau bagian-bagian yang terpenting dari system tersebut yang masih tetap bertahan. Baileu menjadi bangunan penting yang terletak di bagian pusat desa pada seluruh masyarakat adat di wilayah Kecamatan Pulau Saparua. Baileu dapat juga disebut sebagai rumah adat yang adalah bentuk manifestasi fisik dari desa sebagai persekutuan adat untuk melakukan segala macam bentuk pertemuan dan upacara adat atau ritual di bangunan tersebut, guna kepentingan masyarakat desa.
\end{abstract}

Kata kunci : Baileu, karakter budaya, sistem adat, manifestasi fisik.

\begin{abstract}
In some villages in the subdistrict found Saparua, awareness and traditional characters are already lost. This is illustrated by the more modern architecture, as well as the lack of attention from community supporters. This is consistent with the fact that major changes have occurred in the indigenous system in villages and districts Saparua only elements or important parts of the system that still survive. Baileu become important buildings are located at the center of the entire indigenous villages in the subdistrict Saparua. Baileu can also be referred to as a custom home is a physical manifestation of the village as a community indigenous to do all kinds of meetings and ceremonies or rituals in the building, in the interests of the villagers.
\end{abstract}

Key Words: Baileu, traditional characters, indigenous system, physical manifestation

\section{PENDAHULUAN}

\section{Latar Belakang}

Usaha-usaha pengembangan dan pelestarian kebudayaan semakin gencar dilakukan oleh pemerintah kini, baik itu upaya pelestarian peninggalan sejarah purbakala berupa pemugaran benteng, gereja, masjid dan lain sebagainya. Demikian pula telah dilakukan inventarisasi kebudayaan daerah, seperti, tarian rakyat, pakaian tradisional, permainan rakyat, serita rakyat, makanan khas daerah dan lain sebagainya. Namun semua ini masih jauh dari yang diharapkan, karena masih banyak hal yang belum dapat tertangani atau masih banyak kendala yang dihadapi dan masih banyak warisan budaya yang belum diinventarisir dan dilestarikan. Di lain pihak, ada terdapat masyarakat adat sebagai pendukung warisan budaya, terutama generasi tua, karena mempunyai 
keinginan untuk tetap mempertahankan dan melestarikan budaya tersebut. Sedangkan sebagian generasi muda cenderung untuk lebih terbuka dan siap mengadakan pembaharuan kebudayaan karena telah terpengaruh dengan perkembangan global, sehingga sudah tidak lagi memperhatikan dan menjaga nilai budaya yang telah ada sejak lama.

Seiring dan sejalan dengan visi dan misi kementerian kebudayaan dan pariwisata "kenali dirimu cintai negerimu", maka modal tradisi budaya yang telah berakar di dalam masyarakat adat harus tetap dipertahankan. Salah satunya adalah baileu, yang sangat memiliki arti penting dalam pencitraan rumah adat orang Maluku. Dimana baileu dapa difungsikan sebagai tempat bermusyawarah untuk menyalurkan aspirasi masyarakat desa dan sebagai tempat pelestarian adat istiada yang terdapat di wilayah tersebut (Dyk, 1962). Untuk itu penelitian tentang baileu di wilayah Pulau Saparua sangat perlu dilakukan demi pengembangan budaya lokal kini serta dapat menunjang data arkeologi Maluku pada umumnya.

Untuk mempermudah kajian tentang tinggalan baileu di Maluku Tengah, maka secara spasial subjek kajian akan mencakup secara khusus tentang Pulau Saparua. Bertitik tolak dari latar belakang yang telah dikemukakan, maka dapat ditemukan permasalahan yang berkaitan erat dengan baileu sebagai bentuk manifestasi fisik dar masyarakat adat di pulau Saparua, yaitu: bagaimanakah gaya konstruksi baileu dan peranannya di dalam masyarakat?

Tujuan dari penelitian ini dimaksudkan untuk dapat mengetahui peranan baileu dalan masyarakat adat, dan dapat juga mengetahui tentang gaya arsitektur Sedangkan Manfaa dari penelitian ini, kiranya diharapkan mampu memberikan kontribusi bagi pengembangan data arkeologi dan budaya lokal Maluku.

Cooley mengatakan bahwa Baileu berasal dari bahasa melayu, yaitu balai atau bale yang berarti tempat pertemuan (Cooley, 1961). Pandangan tersebut dapat diakui kebenarannya karena fungsi dari baileu adalah sama dengan balai, yaitu sebagai tempat pertemuan. Karena berdasar etimolgi, kata baileu dan balai tidak berbeda jauh Perubahan dari kata balai menjadi baileu, mungkin karena proses "Malukunisasi", sama saja dengan kata "rumah" menjadi "luma".

\section{Metode Penelitian}

Secara geografis, pulau Saparua terletak di gugusan kepulauan Lease, yang berada di wilayah administratif Kabupaten Maluku Tengah. Untuk mencapai wilayah tersebut, dapat ditempuh dengan perjalanan laut dari desa Tulehu yang berada di Pulau Ambon selama \pm 30 menit.

Pengumpulan data dilakukan dengan tiga cara yakni pengumpulan data melalu studi pustaka, pengumpulan data dengan mengadakan kunjungan langsung ke lokasi penelitian (observasi langsung) dan teknik komunikasi langsung.

1. Studi Pustaka

Sumber data didapatkan melalui studi literatur, yaitu pencarian dan pengumpulan tiap laporan atau hasi penelitian maupun arsip yang berkaitan dengan sejarah dan budaya masyarakat pulau Saparua.

2. Observasi langsung.

Pengumpulan data lapangan dilaksanakan dengan cara survey, dimana peneliti melakukan pengamatan secara langsung guna mengetahui secara pasti perkembangan baileu di pulau Saparua kini.

Tahapan ini diawali dengan memproses kembali data primer dan sekunde yang telah direkam pada tahap pengumpulan data, antara lain dengan menganalisa dan mengkoherensikan informasi dari objek penelitian lapangan dengan referensi buku yang menjadi bahan mendukung penelitian. Untuk analisis data, dipilih teknik dan prosedur yang sesuai dengan tujuan dan tuntutan penelitian sebagaimana yang telah dirumuskan dalam rancangan penelitian. Analisis data akan menghasilkan risalah cuplikan setelah diolah melalui deskriptif penelitian. Risalah cuplikan kemudian diolah lebih lanjut dengan mencari korelasi atau kecenderungan hubungan antar variabel tertentu, antara lain melalui penerapan deskriptif analitis. Hingga taraf ini biasanya akan dihasilkan data sejarah dan arkeologi yang sudah ditempatkan dalam konteks formal (bentuk), spatial (ruang), dan temporal formal (bentuk), spatial (ruang), dan temporal
(waktu) tertentu. Misalnya saja, klasifikasi (waktu) tertentu. Misalnya saja, klasifikasi bentuk atau gaya dan ukuran, bahkan juga baileu.

Berdasarkan hasil pengolahan data yang dilakukan, dapat dianalisis bahwa baileu merupakan tempat berkumpul suatu komunitas masyarakat adat karena berperan sebagai alat pemersatu masyarakat dan juga baileu menjadi pusat pelestarian adat istiadat di wilayah tersebut.

\section{HASIL DAN PEMBAHASAN}

Baileu berasal dari bahasa melayu, yaitu balai atau bale yang berarti tempat pertemuan. Pandangan tersebut dapat diakui kebenarannya karena:

- Fungsi dari baileu adalah sama dengan balai, yaitu sebagai tempat pertemuan

- Kata baileu dan balai tidak berbeda jauh. Perubahan dari kata balai menjadi baileu, mungkin karena proses "Malukunisasi", sama saja dengan kata "rumah" menjadi "luma".

Hampir sebagian besar baileu di Pulau Saparua, lantainya dibuat lebih tinggi. Keadaan ini dimaksudkan agar tidak mudah dimasuki binatang, agar masyarakat yang berada di halaman baileu dapat melihat kegiatan yang sementara berlangsung di dalam baileu dan menandakan bahwa roh-roh nenek moyang lebih tinggi daripada manusia (Cooley, 1962).

Berdasarkan pendapat tersebut, dapat dianalisis bahwa baileu merupakan suatu bangunan yang tak berdinding. Mungkin diciptakan dengan maksud agar supaya rohroh nenek moyang lebih leluasa masuk dan keluar baileu. Untuk mencegah masuknya binatang ke dalam baileu, maka satu-satunya jalan yang harus ditempuh adalah baileu harus dibuat lebih tinggi. Mengingat bahwa salah satu fungsi baileu adalah sebagai sarana komunikasi dengan roh-roh nenek moyang, maka konstruksinya harus dibuat berbed dengan rumah biasa atau rumah tinggal.

Pada beberapa baileu di pulau Saparua, ada terdapat beberapa benda tinggalan arkeologi, seperti meriam dan tempayan, seperti yang terdapat di desa Ouw. Hampi sebagian besar baileu yang tersebar di pulau Saparua ada terdapat batu pamali. Batu pamal adalah batu yang permukaannya rata dan terletak beberapa meter dari bangunan baileu, dapat diartikan juga sebagai batu tabu atau pantangan. Menurut kepercayaan masyarakat setempat, bahwa batu pamali dianggap memang mempunyai kekuatan gaib sehingga disebut batu pantangan. Hal ini memang dapat dimengerti karena apabila diteliti, maka ternyata batu pamali pada mulanya berfungsi sebagai mezbah persembahan kepada roh-roh nenek moyang atau dapat disebut juga sebagai dolmen.

\section{Baileu Patasiwa dan Baileu Patalima}

Ada terdapat dua ciri bangunan baileu yang tersebar di seluruh wilayah Maluku Tengah, yaitu Baileu Patasiwa dan Baileu Patalima (Cooley, 1984). Setiap desa di Pulau Saparua tergolong pada ciri tersebut, baik itu Patasiwa maupun Patalima. Pola adat patasiwa dan patalima pada hakekatnya adalah berbeda sehingga dengan sendirinya ada terjadi perbedaan didalamnya Berdasarkan keterangan yang dihimpun dar beberapa kepala adat di desa Saparua, ciriciri perbedaan baileu patasiwa dan patalima antara lain sebagai berikut:

- Batu pamali baileu patasiwa terletak pada bagian "matahari naik" (istilah daerah) artinya batu pamali yang terletak di halaman baileu berada antara tempat terbitnya matahar dengan bangunan baileu, dengan kata lain berarti batu pamali terletak di 
bagian timur baileu.

- Batu pamali patalima terletak pada bagian "matahari masuk" artinya batu pamali terletak antara tempa terbenamnyaa matahari dengan baileu, dengan pengertian lain berarti terletak di bagian barat baileu.

- Batu pamali baileu patasiwa terletak di sebelah darat, artinya batu pamali terletak antara baileu dengan gunung.

- Batu pamali baileu patalima terletak di sebelah laut, artinya batu pamal terletak diantara baileu dengan laut.

- Lantai baileu patasiwa terletak 2 (dua) meter diatas permukaan tanah, biasanya terbuat dari papan, sedangkan lantai baileu patalim berada sama rata dengan tanah.

Dewasa ini tidak semua baileu di pulau Saparua menunjukkan cirri-ciri tersebut, misalnya: desa Tuhaha menurut keterangan tergolong patasiwa, tetapi batu pamali bailleu desa tersebut terletak pad bagian matahari masuk dan berkedudukan $\mathrm{d}$

sebelah laut. Contoh lainnya pada desa Booi dan Paperu, menurut keterangan tergolong patasiwa, tetapi lantai baileu kedua desa tersebut berada sama rata dengan tanah tersebut berada sama rata dengan tanah
dan terletak di sebelah laut. Sehingga dapat diketahui bahwa ada pengecualian pada beberapa desa adat di pulau Saparua yang sudah tidak lagi mencirikan hal tersebut.

\section{Gaya Konstruksi Baileu}

Ditinjau dari gaya konstruksinya, maka baileu dapat dibagi menjadi 3 (tiga) macam, yaitu: baileu yang lantainya tergantung (seperti panggung), baileu yang lantainya terbuat dari semen seperti rumah tinggal dan baileu yang lantainya sejajar dengan tanah.

a. Baileu yang lantainya tergantung. Pada umumnya baileu seperti ini terletak $1-1,5$ meter diatas permukaan tanah dan di topang oleh balok kayu berdiameter $15 \mathrm{~cm}$, dan berlantai papan Pada umumnya konstruksibaileuberbentuk Pang panggung ini dibuat dari jenis kayu keras, dimana dalam bahasa lokal disebut kayu nani dan kayu samar. Salah satu perbedaan

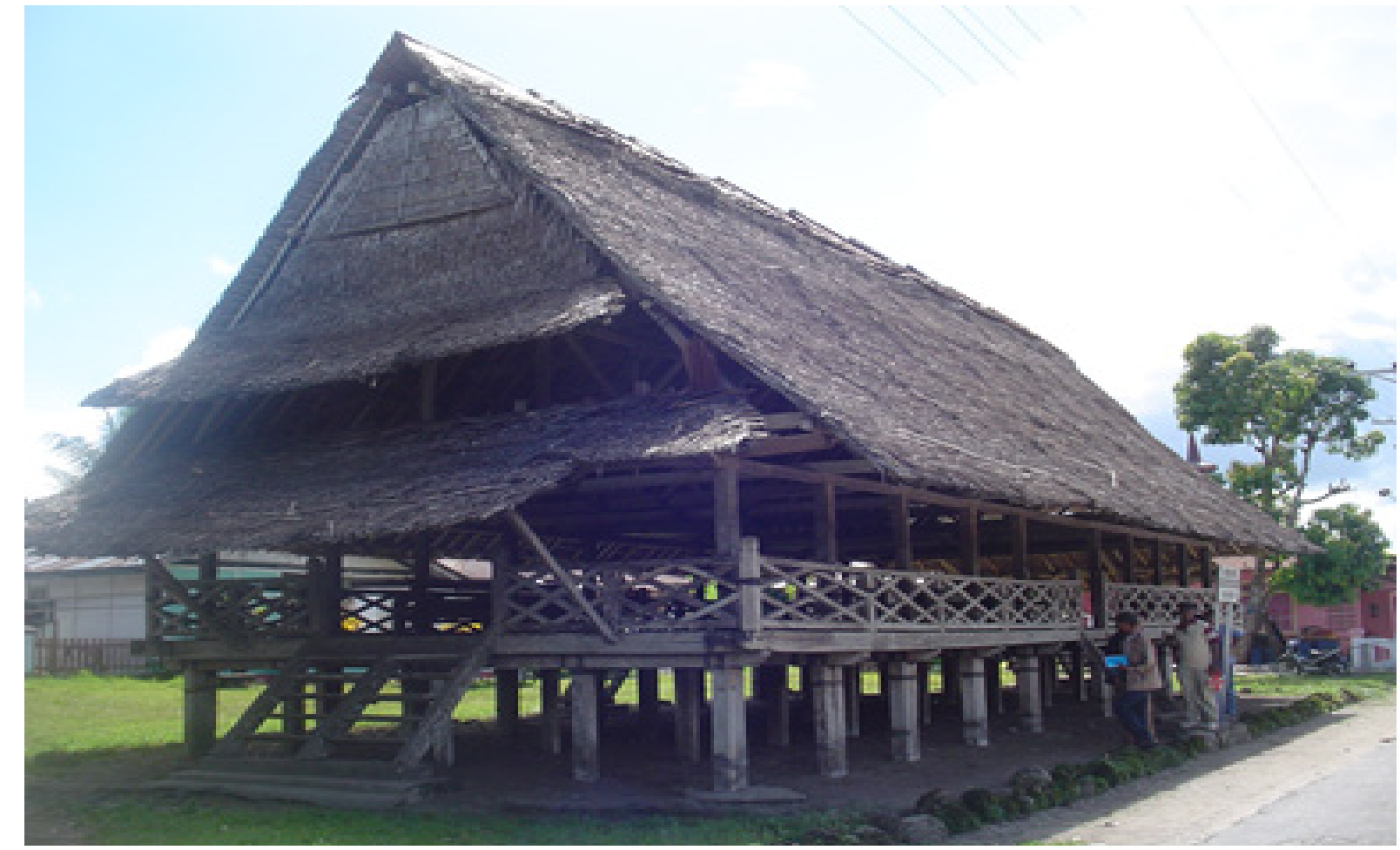

Foto 1. Baileu desa Nolloth penting dari bangunan baileu berbentuk panggung dengan kedua jenis baileu lainnya adalah terletak pada ukuran luas lainnya adalah terletak pada ukuran luas
bangunannya, hal ini dikarenakan oleh bangunannya, hal ini dikarenakan oleh
ukuran luas baileu berbentuk panggung lebih besar, bahkan ada yang ukuran panjang bangunannya lebih dari 10 meter dan ukurannya lebih tinggi dari atas permukaan tanah.

Dapat dikatakan baileu seperti ini berkonstruksi asli dan mengikuti pola ciri khas kehidupan masyarakat austronesia yang tinggal pada rumah-rumah berbentuk panggung. Baileu dengan gaya bangunan tersebut dapat dijumpai di desa Nolloth, Haria dan Siri Haria dan Siri-sori Sarani. Biasanya jumlah tiang dalam baileu berhubungan
erat dengan jumlah mata rumah penting di dalam desa tersebut.

b. Baileu yang lantainya dibuat dari semen.

Baileu dengan gaya seperti ini adalah baileu yang sudah dimodernisir, dengan kata lain baileu tersebut sudah berubah bentuk dari berlantai papan menjadi lantai semen. Jadi meskipun kini lantainya terbuat dari semen, tetapi lantai tersebut tetap tinggi seperti semula. Ukuran panjang pada baileu jenis ini lebih kecil, jika dibandingkan dengan ukuran baileu berbentuk panggung, yaitu dengan ukuran berbentuk panggung, yaitu dengan ukuran
panjang maksimal 10 meter. Baileu dengan gaya bangunan seperti ini Nampak pada baileu desa Ihamahu dan Tuhaha.

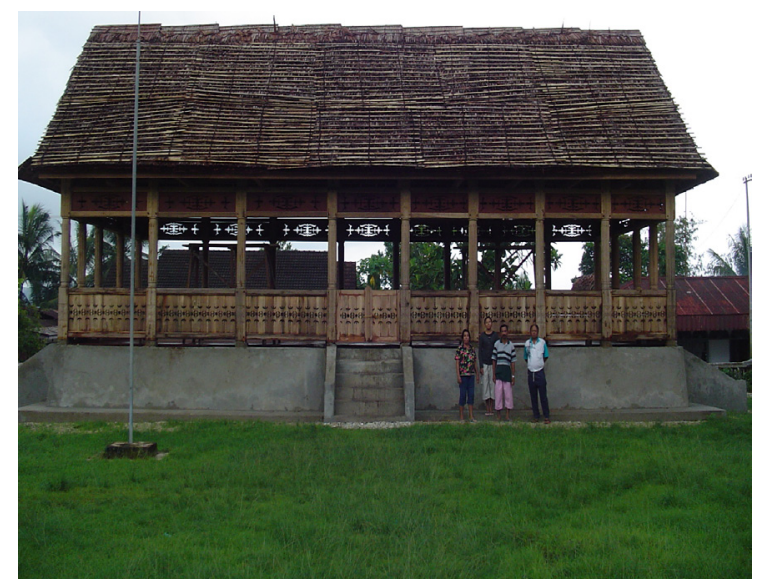

Foto 2. Baileu desa Ihamahu Tuhaha

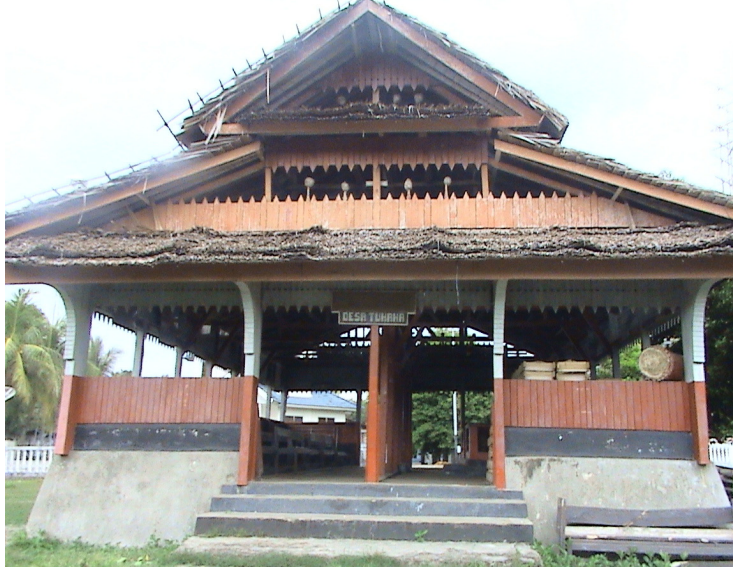

Foto 3. Baileu desa Tuhaha

c. Baileu yang lantainya sama rata dengan anah

Baileu dengan gaya bangunan sepert ini terdapat di desa Porto dan Booy, dan yang lebih mencengangkan adalah bahan penutup baileu yang seharusnya adalah atap, namun telah diganti dengan senk, sehingga telah hilang unsur ketradisionalannya. Ukuran panjang pada baileu jenis ini jauh lebih kecil, jika dibandingkan dengan ukuran baileu berbentuk panggung dan baileu barlanta semen, yaitu dengan ukuran panjang maksimal 8 meter.

Peranan Baileu di dalam masyarakat adat

Kedudukan baileu pada suat masyarakat adat terasa sangat berarti didalam pembentukan moralitas dan pengembangan diri dari suatu komunitas masyarakat, dengan kata lain baileu menjadi alat pemersatu dan lambang demokrasi, sebagai pusat upacara adat dan dapat juga menjadi objek wisata yang cukup menarik bagi pengembangan desa tersebut. Berikut ini adalah 3 (tiga) peranan baileu dalam suatu masyarakat adat:

1. Baileu sebagai alat pemersatu dan lambang demokrasi

Sebagaimana telah kemukakan oleh Cooley bahwa baileu adalah tempat berkumpul dan bermusyawarah. Pada kenyataannya, jelas bahwa baileu selalu dipergunakan sebagai tempat berkumpul masyarakat guna membahas masalah-masalah yang sedang 


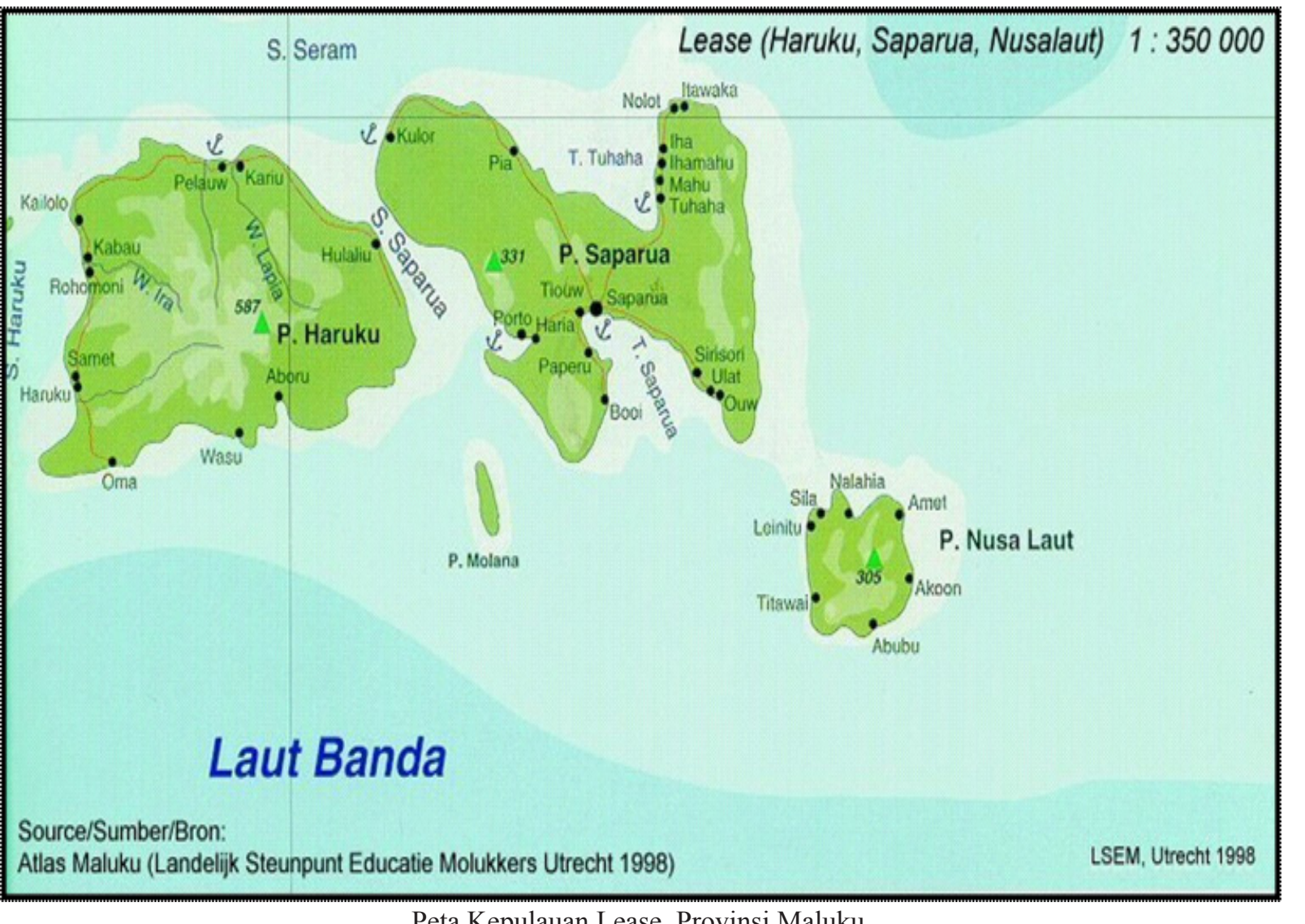

Peta Kepulauan Lease, Provinsi Maluku

terjadi di dalam desa tersebut. Misalnya salah satu desa mengalami persengketaan dengan desa tetangga tentang batas tanah, maka para pemangku adat akan berkumpul di baileu guna bermusyawarah membahas hal tersebut, sehingga tiap putusan yang diambil adalah dengan cara demokrasi. Pada umumnya suasana musyawarah di baileu berbeda dengan suasana rapat atau musyawarah $\mathrm{d}$ tempat lain, karena jelas bahwa musyawarah yang dilaksanakan di baileu diliputi dengan suasana adat. Demikianlah baileu sebagai gedung DPR desa dapat merupakan suatu inspirasi untuk memajukan kepentingan masyarakat menjadi lebih baik. Hal ini juga dapat menjadi bukti nyata yang sangat luar biasa kepada dunia luar, bahwa demokrasi telah hidup dan berkembang di Maluku sejak lama.

2. Baileu sebagai pusat upacara adat Baileu adalah tempat untuk melaksanakan upacara-upacara adat dan sarana komunikasi dengan roh-roh nenek moyang, sehingga baileu dapat dikatakan sebagai pusat upacara adat dalam suatu komunitas adat di wilayah Maluku Tengah. Untuk mendapat gambaran yang jelas tentang hal ini, akan dikemukakan beberapa upacara yang biasa diadakan di baileu, yaitu:

- Upacara membawa kain berkat, yaitu upacara yang berhubungan dengan adat perkawinan, dan merupakan salah satu tuntutan adat yang harus dipenuhi oleh tiap orang di dalam komunitas adat tersebut.

- Upacara tutup sasi, yaitu larangan atau seruan kepada masyarakat untuk tidak melanggar peraturan adat yang telah dibuat oleh pemerintah adat (Pattikayhatu, 1993).

- Upacara pelantikan raja, adalah sesuatu ha yang mutlak harus dilaksanakan sebaga syarat pada pemerintahan desa baru dalam suatu masyarakat adat di wilayah Maluku Tengah, khususnya pulau Saparua. Di wilayah Maluku Tengah, upacara pelantikan raja (kepala desa) biasanya melalui 3 (tiga) proses, yaitu: pelantikan secara adat (upacara adat), pelantikan oleh kepala kecamatan (upacara sipil) dan pemberkatan secara agama (Sachse, 1907).

\section{Baileu sebagai objek pariwisata}

Sesuai dengan visi dan misi Kementerian Kebudayaan dan Pariwisata kini "Kenali Dirimu Cintai Negerimu", terasa sangat mendukung pengembangan kebudayaan daerah. Salah satu adalah baileu yang menjadi objek kekayaan budaya bangsa dengan memiliki keunikan tersendiri yang belum tentu dapat dijumpai pada daerah lain di Indonesia. Keunikan tersebut dapat menjadi objek wisata handal yang patut dikedepankan dalam pengembangan daerah. Sebagai objek wisata, baileu dapat menyajikan wujudnya sebagai bangunan yang memiliki cirri khas tersendiri sebagai rumah adat dan objek yang dapat menyajikan upacara-upacara adat yang menarik.

\section{PENUTUP}

Baileu memiliki makna yang sangat berarti bagi masyarakat adat di wilayah Maluku tengah, khususnya pada masyarakat pulau Saparua, karena berfungsi sebagai tempat berkumpul masyarakat didalam membahas suatu masalah yang terjadi di dalam desa. Baileu juga dapat menjadi sarana pendukung dalam proses upacara adat, baik itu acara pernikahan maupun acara pelantikan raja dan lain sebagainya.

Terdapat dua ciri bangunan baileu yang tersebar di seluruh wilayah Maluku Tengah, yaitu Baileu Patasiwa dan Baileu Patalima. Setiap desa di Pulau Saparua tergolong pada ciri tersebut, baik itu Patasiwa maupun Patalima. Dari uraian yang telah disampaikan, dapat dikatakan bawa baileu di Saparua pada kenyataanya kini terdapat 2 (dua) kategori, yaitu:

1. Baileu yang masih dipertahankan keasliannya dalam segala aspek, baik dari segi arsitekturnya maupun ornamenornamennya.

2. Baileu yang arsitektur bangunannya telah dirubah dari gaya keasliaanya dengan memakai bahan dasar kayu dan digant dengan bahan semen dan senk.

Sebaiknya gaya bangunan baileu harus mengikuti pola adat yang berlaku, yaitu dengan berlandaskan akan ketradisionalan, bukan dengan pengembangan gaya bangunan yang sudah dimodifikasi dengan cara yang lebih modern. Untuk itu sekiranya diharapkan kepada masyarakat selaku pendukung budaya, harus menjaga dan melestarikan karya budaya tersebut. 


\section{DAFTAR PUSTAKA}

Cooley, F. L. 1987. Mimbar dan Tahta. Hubungan Lembaga-Lembaga Keagamaan di Maluku Tengah. Jakarta: Pustaka Sinar Harapan.

Ambonese Adat a General Description, Yale University, New Haven Coon, 1962.

Dyk, V. R. 1962. Pengantar Hukum Adat Indonesia. Sumur Bandung.

Maluku Tengah Di Masa Lampau: Gambaran Sekilas Lewat Arsip Abad Sembilan Belas, penerbitan sumber-sumber sejarah, No. 13. Arsip Nasional Republik Indonesia, Jakarta, 1982.

Pattikayhatu, J. A. 1993. Sejarah Daerah Maluku. Ambon: Departemen Pendidikan dan Kebudayaan.

Sachse, F. J. P. 1907. Het Eiland Seram en Zijne Bewoners. Edisi Boekhandel en Drukkerij. 